WILLARD L. RODGERS * *

\title{
DENSITY, CROWDING, AND SATISFACTION WITH THE RESIDENTIAL ENVIRONMENT *
}

(Received 4 October, 1980)

\begin{abstract}
The relationships between a set of measures of various components of environmental density and perceived crowding are examined in a data set from a sample of residents of a large metropolitan area. While there are meaningful patterns observed among the correlations, the primary finding is the weakness of the relationships between density and crowding. The implications of the weak relationship between objective and subjective measures intended to measure components of the quality of life, of which the present findings are an example, are discussed; the usefulness of subjective measures may lie primarily in their capacity to define what aspects of society should be monitored and included in a system of social accounting.
\end{abstract}

Studies of animals of a variety of species have revealed a variety of pathological consequences of living under densely populated conditions. Studies of density effects among humans, however, have yielded much more ambiguous findings. Some studies have shown what appear to be undesirable effects of high density, while other studies have failed to reveal such consequences or have shown that the consequences can more easily be interpreted in terms of other factors associated with density, such as poverty. Several extensive reviews of these studies and theoretical interpretations of the effects of density on humans are available (Baldassare, 1978; Lawrence, 1974; Fischeret al., 1975; Freedman, 1973). While there are few generalizations that would go unchallenged based on past studies of human density, it does seem clear that crowding is not a unidimensional concept. A distinction should be made between objective density and subjective crowding (see, for example, Rapoport, 1975; Day and Day, 1973; Marans and Mandell, 1972). (Perceived) crowding is related to (objective) density measures, such as number of persons per unit area, but also depends, apparently, on a wide variety of cultural norms, individual expectation levels, and other factors.

A general framework for examining the relationship between the objective environment and satisfaction with that environment (French et al., 1974) is useful in this context. In the terms of that framework, the objective environment - in this case density - is perceived by the individual, but with some 
degree of inaccuracy. Sources of inaccuracy include random factors, and also motivational factors, or biases. The manner in which the perceived environment is evaluated by the individual depends on the fit between that perception and the needs and values of the individual. This framework is useful in thinking about why different individuals living or working in environments characterized by the same degree of density may differ so widely in their subjective crowding estimates. These individuals may differ in types of environments in which they have lived in the past, and may also differ in their needs for privacy, for affiliation, and so on.

Not only is it important to distinguish between density and crowding, it may also be important to distinguish among various components of density. Galle et al. (1972) describe four components which make up the overall measure (i.e., population per unit area) often used as the single indicator of density. These components are as follows: (a) intrahousehold density, usually expressed in terms of persons per room; (b) dwelling unit size, usually expressed in terms of number of rooms; (c) the number of housing units within a given structure; and (d) the number of residential structures per unit area. Failure to distinguish among these various components may lead to failure to detect certain types of effects of population density, or to apparently conflicting results between different studies. For example, size of place is related to the overall measure of objective density, but not to each of the components enumerated above. Specifically, it has been noted that although the number of persons per unit area is obviously higher in urban areas than in rural areas, the number of persons per room is no higher in central cities or in metropolitan areas than it is for the United States as a whole (Carnahan et al., 1974). It is this aspect of density, which Galle et al. (1972) refer to as a measure of 'interpersonal press', that those authors found to be the most important component of overall density as a 'determinant' of four of their five measures of social pathology: standardized mortality rate, fertility rate, public assistance rate, and detected juvenile delinquency rate. ${ }^{1}$ (Their fifth measure of pathology, rate of admission to mental hospitals, was most strongly related to the number of rooms per housing unit.) Moreover, the relationship of the intrahousehold component with each of those four indicators of pathology was much stronger than that of the overall density measure.

In a study at the individual level, using data from respondents sampled from a stratified selection of census tracts in Chicago, Gove et al. (1979) found that intrahousehold density and two aspects of subjective crowding 
within the home are related to a wide variety of measures of mental health, social relationships (especially within but also outside the home), quality of child care, and self-reported physical health. Most of these relationships persisted even after controlling on several demographic variables, and uniquely explained about as much variance in most measures as did the entire set of demographics.

In contrast, Schmitt (1966), using census tract data for the Honolulu Standard Metropolitan Statistical Area, found that the overall population density measure was more strongly related to eight of nine measures of health and social disorganization than was the component, persons per room. ${ }^{2}$ Somewhat similar conclusions were reached by Booth and Cowell (1976) from analysis of individual data collected from a sample of Toronto families. They examined relationships between a variety of density measures and illness behavior, morbidity, psychoendocrine indicators of stress gathered through personal interviews and medical examinations. Only a few of the correlations were significant, but those that were significant suggest that intrahousehold density and crowding (i.e., objective and subjective factors) may have decremental effects on health under certain conditions, whereas neighborhood density and crowding have no detectable effects.

The evidence, then, is ambiguous about the relationship between density and indicators of pathology. Schmitt found that population density per unit area is quite strongly related to several such indicators, whereas Galle et al., found this overall measure was only weakly correlated to their set of indicators, and that the key component is intrahousehold density.

\section{STATEMENT OF ISSUES}

Several issues concerning the relationships among crowding, and satisfaction with the residential environment will be examined in this paper, using data from one particular metropolitan area. One set of issues concerns how overall density and its various components are related to measures of (perceived) crowding. Another set of issues concerns how the measures of density and crowding are related to measures of satisfaction with the residential environment as a whole. Of particular interest is the question of whether all of the possible effects of objective density with respect to residential satisfaction are mediated by the measures of subjective crowding. 


\section{METHODOLOGY}

The data that will be examined in this study come from a study which was conducted in the Detroit metropolitan area. ${ }^{3}$ The sample design involved stratification with a higher sampling rate in the central city than in the rest of the area, so as to allow adequate samples from both strata. Personal interviews were conducted by University of Michigan Survey Research Center interviewers with either the head of the selected households or with the spouse of the head, with random assignment of the person to be interviewed. Interviews were obtained from 1194 respondents during the period from October, 1974 through February, 1975. The overall response rate was 70 percent.

\section{Measures of Density}

Measures of objective density were obtained primarily from census data at the tract level collected in 1970. The area of each tract within which one or more respondents resided was calculated from maps. Overall population density was calculated by dividing the total 1970 population of that tract by the size of the tract in square miles. ${ }^{4}$

With respect to the components of density enumerated by Galle et al. (1972), several measures of intrahousehold density are available. The first of these is simply the number of people per housing unit, from the 1970 census data. Another variable is the proportion of housing units within each tract with no more than one person per room - an indicator of low density housing; and another, the proportion of housing units with 1.5 or more persons per room - an indicator of high density housing. Finally for each respondent interviewed as part of this study, an individual household measure of density was available: the number of persons per room within the housing unit.

The average number of rooms per household was obtained from census data for each census tract within which respondents were living. Respondents were asked for the number of rooms within their own homes or apartments.

The combination of the first two density components (persons per room and rooms per housing unit) is the population per housing unit, and measures of this combination were obtained for each census tract and for the household of each respondent.

Only crude indicators of the third density component, housing units per 
structure, were available. For each census tract, the proportion of housing units that were single family units (houses or trailers) was obtained. Each respondent's housing unit was characterized as being a single family structure or part of a multi-unit structure. (More detailed categorizations were actually made by the interviewers, but proved not to be useful in the analysis.)

The final component of density is the number of housing units per unit area. The number of housing units within each tract in 1970 was divided by the area of that tract to obtain the number of housing units per square mile. Another indicator of this component which is more specific to the individual respondents is an estimate by the interviewers of the distance between the building within which the respondent lives and the next building.

\section{Measures of Crowding}

Respondents were asked to describe both the community within which they lived and their immediate neighborhoods on a number of scales, using a semantic differential type format. In both cases, one of the scales was defined by the terms 'crowded' and 'uncrowded'. Respondents were asked to check a box between these two end points and were given scores ranging from 1 (least crowded) to 7 (most crowded). The respondents were also asked a question that is relevant to perceived crowding within their own homes: the extent to which they thought that there was sufficient space to do the things they wanted to do. ${ }^{5}$

\section{Measures of Satisfaction with the Residential Environment}

The respondents were asked a variety of questions that were aimed at tapping their overall levels of satisfaction with their residential environments. With respect to their satisfaction with their community as a whole, they were asked three questions in the semantic differential format: they were asked to describe their communities as 'attractive' or 'unattractive'; as a 'very good place to live' or a 'very poor place to live'; and as 'pleasant' or 'unpleasant'. They were also asked to assess their overall level of satisfaction with their community, on a scale ranging from 'completely dissatisfied' through 'neutral' up to 'completely satisfied'. The relationships among these four variables were found to be substantial (average correlation coefficient $=0.65$, reliability coefficient alpha $=0.88$ ) and stable across various subgroups of the sample, 
thereby providing justification for combining the items into an index of community satisfaction.

Respondents were also asked to describe their immediate neighborhoods on three of the same four items they were asked about the community as a whole. (The semantic differential description ranging from 'attractive' to 'unattractive' was not asked with reference to the neighborhood.) The correlations among these three items were all substantial (average correlation coefficient $=0.68$, reliability coefficient alpha $=0.86$ ), and once again they were combined into an index of overall satisfaction with the neighborhood.

Respondents were also asked to assess their overall satisfaction with their own homes, but were not asked any other global evaluative items about their homes.

\section{FINDINGS}

\section{Correlations between Density Components and Crowding}

The relationships among the various density measures and the perceptions of crowding within the residential environment were examined. As shown in Table I, most of these relationships are adequately summarized by simple correlation coefficients. The correlation coefficients capture only the linear aspects of the relationships, but with a few minor exceptions there were no significant increments in explanatory power when quadratic terms were included to check for curvilinearities. (One of the exceptions, for example, is the relationship between number of persons in the household and perception of crowding within the city or township. Respondents living in households with a total of three to five persons tended to report that their communities were less crowded than did respondents living in households that were either smaller or larger. A possible meaning of this curvilinearity will be suggested in later discussion.)

The most important conclusion that can be drawn from Table I is that the relationships between measures of objective density and perceived crowding are very low. The correlation between crowding in the community and overall population density is represented by a correlation coefficient of only 0.26 . This implies that many factors other than density affect the individual's perception of the crowdedness of his residential environment. The low correlation may in part be explained by measurement error: the same 


\section{TABLE I}

Relationships between objective density measures and perceived crowding (correlation coefficients) ${ }^{\mathrm{a}}$

\begin{tabular}{lll}
\hline $\begin{array}{l}\text { Crowding in } \\
\text { city or town- } \\
\text { ships }\end{array}$ & $\begin{array}{l}\text { Crowding in } \\
\text { neighborhood home }\end{array}$ & $\begin{array}{l}\text { Crowding within } \\
\text { home }\end{array}$ \\
\hline
\end{tabular}

Overall density

Census tract: persons per square

mile

$\begin{array}{ll}0.26 & 0.16\end{array}$

$(0.07)$

Intrahousehold density

Census tract: proportion of housing

units with 1.5 or more persons

per room

Multiple $R^{\mathrm{b}}$

Census tract: proportion of housing

units with 1.0 or more persons

per room

Respondent's home: persons per

room

Size of housing units, in rooms

Census tract; average

$-0.10$

0.40

Multiple $R^{\mathrm{b}}$

Respondent's home

$-0.12$

$-0.10$

$-0.08$

Population per housing unit

Census tract: average

$-0.12$

$(-0.01)$

$(-0.03)$

$(0.05)$

0.13

Respondent's household

Multiple $R^{\mathrm{b}}$

0.10

Housing units per structure

Census tract: proportion single

family homes

$-0.18$

$-0.13$

0.15

$(0.00)$

Respondent's home: single family

house?

$-0.16$

$-0.15$

Structures per unit area

Respondent: Distance from

structure in which respondent

lives to nearest building

$-0.16$

Housing unit density

Census tract: housing units

per square mile Multiple $R^{b}$

0.26

$(0.01$ )

0.24

a Correlation coefficients enclosed in parentheses are not significant at the 0.05 level. In determining the significance of these terms, the sample size was divided by a factor of 1.5 to take account of the design effect resulting from the complex sample design psed in the data collection.

Multiple $R$ 's using both linear and quadratic terms as predictors. Multiple $R$ 's are shown if and only if the quadratic term contributed a statistically significant increment to the explanatory power of the linear density term. 
respondent would give a slightly different answer on different days or in response to slightly different questions; and density doubtless changed for some areas between the time of the 1970 census and the 1974 interviews. It is likely, however, that characteristics of the individuals and of the environment in which they live, in addition to density, affect their perceptions of crowding.

Table I also shows that the most important component of density with respect to perceptions of crowding within the city or township and within the local neighborhood is the density of housing units within the area. Closely linked $(r=0.66)$ to the density of housing units is the proportion of housing units which consist of single family houses, and this measure of density is also related to crowding: the greater the proportion of single family houses, the less crowded the environment is perceived to be. This suggests an explanation for the curvilinearity of the relationship between number of persons within households and perceived crowding; families, typically with two or three children, tend to live in areas consisting primarily of single family housing, while single adults and married couples without children or whose children have left home are more likely to live in apartment structures, and therefore in neighborhoods that have a high density of housing units. At the other extreme, households with six or more members also tend to be in neighborhoods with high densities of housing units.

The strongest correlate of the respondent's perception of crowding within his own home is intrahousehold density. Not surprisingly, the specific measure that is related to this perception is unique to the individual's own housing situation; the proportions of households within the census tract as a whole that have high or low densities are only very weakly correlated with the perception of crowding, and even those correlations all but disappear when the part correlations are examined, after removing the effect of the density within the respondent's own dwelling unit from his perception of crowding.

\section{Multivariate Prediction from Density Measures to Crowding Perceptions}

Having examined the bivariate relationships between the various measures of density and the perceptions of crowding, the next question concerns the total explanatory power of the entire set of density measures. Stepwise multiple regression was used to select the set of density measures that explain the highest proportion of variance in each of the three perceptions of crowding. The findings from these analyses are shown in Table II. 
TABLE II

Multivariate regression analyses, perceived crowding measures predicted by density (standardized regression coefficients)

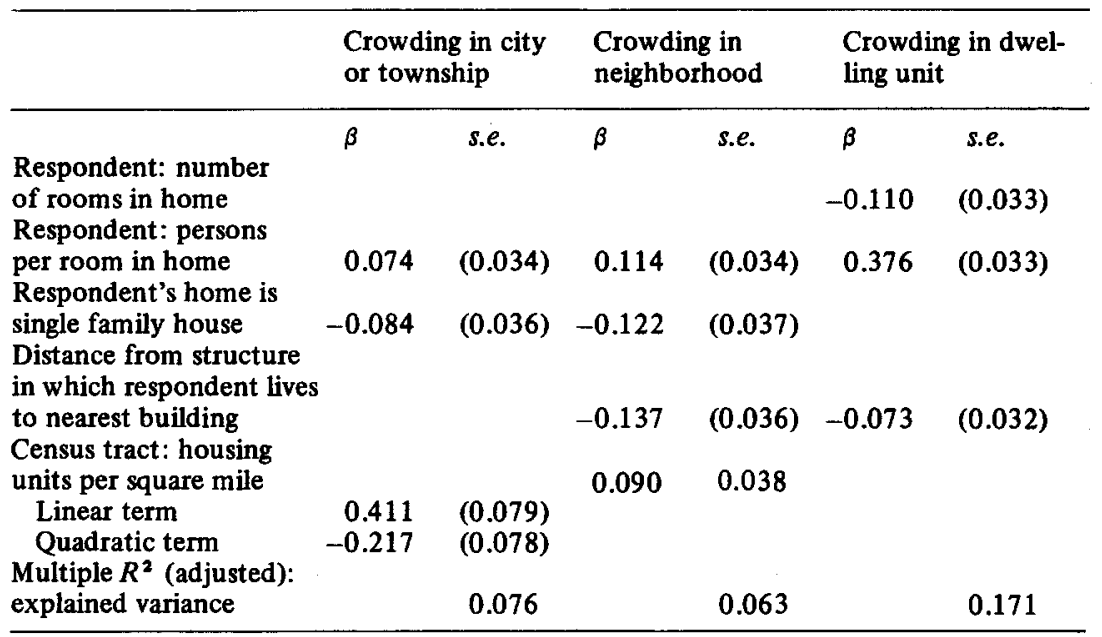

a The variables for which regression coefficients are shown in each column are those selected in stepwise multiple regression analyses in which all of the density variables (listed in Table 1) were eligible as predictors. Only coefficients that are significantly different from zero at the 0.05 level are shown; the stepwise multiple regression was stopped when no additional predictors were significant at that level. Tests of significance, and the standard errors of the coefficients shown above, are based on the sample size divided by a factor of 1.5 , as explained in the footnote to Table I.

Altogether, the density measures are able to explain less than eight percent of the variance in the perceptions of crowding within the city or township. As suggested by the bivariate relationships, the most important component of density with respect to this measure of crowding is the number of housing units per square mile. This relationship is curvilinear, with the highest perception of crowding expressed by those living in census tracts with densities of about 10000 housing units per square mile. Additional explanatory power is contributed by the respondents' individual housing situations: whether or not they lived in a single family house; and intrahousehold density, as measured by persons per room.

The density measure with the highest standardized regression coefficient with respect to perceived crowding within the neighborhood is the distance from the building in which the respondent lives to the nearest building. Otherwise, the same three density measures that predicted perceptions of commu- 
nity crowding also predict perceptions of neighborhood crowding. The density of housing units within the census tract shows an apparently linear, rather than curvilinear, relationship with neighborhood crowding, and is somewhat less important as a predictor of neighborhood crowding than as a predictor of community crowding. Measures of characteristics of the respondent's immediate household situation, on the other hand, are somewhat more important as predictors of neighborhood satisfaction than as predictors of community satisfaction. Altogether, these four density measures can explain only about six percent of the variance in the measure of neighborhood crowding.

With respect to perceived crowding within the respondent's own housing unit, by far the most important predictor is the number of persons per room within the home. Largely because of this strong correlation, about 17 percent of the variation of this measure of crowding can be explained by the density measures. Also contributing to this predictive power are the number of rooms in the home and the distance between the structure within which the respondent lived and the nearest other structure.

Relationships between Measures of Residential Satisfaction and Measures of Density and Crowding

In the introduction to this paper, evidence for the influence of density and crowding on the evaluation of the residential environment was cited. Confirmatory evidence for these relationships is shown in Table III. Satisfaction with each of the three levels of the residential environment (the community as a whole, the local neighborhood, and the individual dwelling unit) is most strongly related to the perception of crowding at the same level. Each of these three relationships has a magnitude of about 0.40 , indicating a comparatively strong influence of perceived crowding on the way in which the environment is assessed. The relationships between components of objective density and residential satisfaction measures are not as strong as those involving perceived crowding, but almost all of the correlations are statistically significant. Respondents tend to be less satisfied with their communities if they live in areas that have many dwellings per square mile, or in areas with dwelling units which are overcrowded. Those living in areas consisting primarily of single family homes tend to be more satisfied than respondents living in areas with many multi-unit structures. Respondents living in densely populated areas also tend to be less satisfied with their neighborhoods and with their own 
TABLE III

Relationships between residential satisfaction and measures of density and crowding (correlation coefficients) $^{\mathbf{a}}$

\begin{tabular}{|c|c|c|c|}
\hline & $\begin{array}{l}\text { Community } \\
\text { satisfaction }\end{array}$ & $\begin{array}{l}\text { Neighborhood } \\
\text { satisfaction }\end{array}$ & $\begin{array}{l}\text { Dwelling unit } \\
\text { satisfaction }\end{array}$ \\
\hline \multicolumn{4}{|l|}{ Overall density } \\
\hline $\begin{array}{l}\text { Census tract: persons per square } \\
\text { mile }\end{array}$ & -0.28 & -0.28 & -0.15 \\
\hline $\begin{array}{l}\text { Intrahousehold density } \\
\text { Census tract: proportion of } \\
\text { housing units with } 1.5 \text { or more }\end{array}$ & -0.20 & -0.20 & $-0.1 J$ \\
\hline $\begin{array}{l}\text { persons per room } \\
\text { Census tract: proportion of }\end{array}$ & -0.17 & -0.20 & -0.11 \\
\hline $\begin{array}{l}\text { housing units with } 1.0 \text { or more } \\
\text { persons per room } \\
\text { Multiple } R^{\mathrm{b}}\end{array}$ & $\begin{array}{r}-0.08 \\
0.11\end{array}$ & -0.10 & -0.08 \\
\hline Respondent's home: persons & & & \\
\hline $\begin{array}{l}\text { per room } \\
\text { Size of housing units, in rooms }\end{array}$ & $(-0.05)$ & -0.10 & -0.17 \\
\hline $\begin{array}{l}\text { Census tract; }{ }^{\text {average }} \\
\text { Multiple } R\end{array}$ & $\begin{array}{l}0.21 \\
0.23\end{array}$ & 0.22 & 0.08 \\
\hline Respondent's home & 0.10 & 0.18 & 0.12 \\
\hline Multiple $R^{b}$ & 0.12 & 0.22 & \\
\hline \multicolumn{4}{|l|}{ Population per housing unit } \\
\hline Census tract: average & 0.19 & 0.17 & $(0.05)$ \\
\hline Respondent's household & $(0.03)$ & $(-0.04)$ & 0.07 \\
\hline Multiple $R^{\mathrm{b}}$ & 0.09 & 0.10 & \\
\hline \multicolumn{4}{|l|}{ 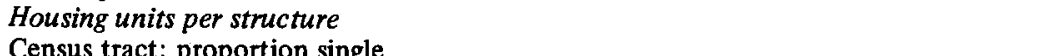 } \\
\hline $\begin{array}{l}\text { family homes } \\
\text { Respondent's home: single }\end{array}$ & 0.24 & 0.30 & 0.12 \\
\hline family home? & 0.19 & 0.21 & 0.12 \\
\hline \multicolumn{4}{|l|}{$\begin{array}{l}\text { Structures per unit area } \\
\text { Respondent: Distance from } \\
\text { structure in which respondent }\end{array}$} \\
\hline lives to nearest building & 0.08 & 0.10 & $(0.07)$ \\
\hline Multiple $R^{\mathrm{b}}$ & 0.13 & 0.14 & \\
\hline \multicolumn{4}{|l|}{ Housing unit density } \\
\hline \multicolumn{4}{|l|}{ Census tract: housing units } \\
\hline $\begin{array}{l}\text { per square mile } \\
\text { Multiple } R^{b}\end{array}$ & $\begin{array}{r}-0.31 \\
0.33\end{array}$ & -0.31 & -0.15 \\
\hline \multicolumn{4}{|l|}{ Perceived crowding } \\
\hline City or township & -0.39 & -0.29 & -0.19 \\
\hline Neighborhood & -0.27 & -0.37 & -0.26 \\
\hline Dwelling unit & -0.19 & -0.26 & -0.42 \\
\hline
\end{tabular}

a Correlation coefficients enclosed in parentheses are not significant at the 0.05 level. In determining the significance of these terms, the sample size was divided by a factor of 1.5 to take account of the design effect resulting from the complex sample design used in the data collection.

Multiple $R$ 's using both linear and quadratic terms as predictors. Multiple $R$ 's are shown if and only if the quadratic term contributed a statistically significant increment to the explanatory power of the linear density term. 
dwelling units than are respondents living in more sparsely populated areas. Those who live in overcrowded units tend to be less satisfied with those homes.

Further analysis shows that some of the relationships between components of objective density and the measures of satisfaction with the overall community and with the local neighborhood are better described as curvilinear rather than as strictly linear. This was demonstrated by a series of regression analysis in which quadratic terms as well as linear terms were used for each of the density components. Those components for which the multiple regression coefficient was significantly higher than the simple bivariate relationship with the linear term are shown in Table III. The shape of the interrelationships is of interest. For example, it appears that satisfaction with the community declines as the number of households per square mile increases up to a level of approximately 10000 units per square mile, and remains relatively flat above that level. Satisfaction with the community and with the neighborhood is highest among those living in homes with approximately eight or nine rooms, and also among those living in structures that are separated from neighboring buildings by a distance of approximately 50 to 100 feet.

\section{Satisfaction with Community}

It is now possible to examine the issue of the extent to which the effects of density are mediated by the perceptions of crowding, as opposed to the effects of density that are mediated by some other psychological mechanism. The procedure that will be followed is first to determine the total effects of the various measures of perceived crowding with respect to a residential satisfaction measure, then to examine the total effects of the objective density measures, and finally to examine the total effects of both density and crowding measures.

The analysis of community satisfaction is shown in Table IV. The three measures of perceived crowding (i.e., at the community, neighborhood, and dwelling unit levels) yield a multiple correlation coefficient with community satisfaction of $R=0.421$, so that these variables are able to explain about 17 percent of the variance in the satisfaction measure. Next, stepwise multiple regression was used to select those components of density which are best able to explain variance in the satisfaction with community measure. It was found that the greater the average number of persons per household 
TABLE IV

Multivariate regression analyses: Satisfaction with the community as predicted by density and crowding (standardized regression coefficients)

\begin{tabular}{|c|c|c|c|c|c|c|}
\hline & \multicolumn{6}{|c|}{ Predictor sets } \\
\hline & \multicolumn{2}{|c|}{$\begin{array}{l}\text { Perceptions of } \\
\text { crowding }\end{array}$} & \multicolumn{2}{|c|}{$\begin{array}{l}\text { Objective density } \\
\text { components }\end{array}$} & \multicolumn{2}{|c|}{$\begin{array}{l}\text { Crowding plus } \\
\text { density }\end{array}$} \\
\hline & $\beta$ & s.e. & $\beta$ & s.e. & $\beta$ & s.e. \\
\hline \multicolumn{7}{|l|}{ Perceptions of crowding } \\
\hline Community & -0.328 & $(0.036)$ & & & -0.276 & $(0.035)$ \\
\hline Neighborhood & -0.110 & $(0.036)$ & & & -0.100 & $(0.035)$ \\
\hline Dwelling unit & -0.107 & $(0.033)$ & & & -0.103 & $(0.032)$ \\
\hline $\begin{array}{l}\text { Objective density com- } \\
\text { ponents } \\
\text { Census tract: proportion } \\
\text { of HU's with } 1.5 \text { or more }\end{array}$ & & & & & & \\
\hline $\begin{array}{l}\text { persons per room } \\
\text { Census tract: popula- }\end{array}$ & & & -0.154 & $(0.037)$ & -0.164 & $(0.034)$ \\
\hline $\begin{array}{l}\text { Census tract: popula- } \\
\text { tion per household } \\
\text { Census tract: HU's per } \\
\text { square mile - }\end{array}$ & & & 0.091 & $(0.040)$ & 0.107 & $(0.037)$ \\
\hline $\begin{array}{l}\text { Linear term } \\
\text { Quadratic term }\end{array}$ & & & $\begin{array}{l}-0.540 \\
+0.350\end{array}$ & $\begin{array}{l}(0.079) \\
(0.078)\end{array}$ & $\begin{array}{r}-0.372 \\
0.274\end{array}$ & $\begin{array}{l}(0.075) \\
(0.073)\end{array}$ \\
\hline $\begin{array}{l}\text { Multiple } R^{2} \text { (adjusted): } \\
\text { explained variance }\end{array}$ & 0.174 & & 0.127 & & 0.248 & \\
\hline
\end{tabular}

a Variables in the first two columns were selected by stepwise multiple regression, stopping when no statistically significant explanatory power was added by any other variable.

within a census tract, the greater the level of satisfaction with the community, but that the proportion of households that were overcrowded in terms of persons per room was negatively related. Finally, both the linear and quadratic terms with respect to the number of housing units per square mile were selected as significant predictors. (The implication of the regression coefficients is that minimum satisfaction is expressed by people in the census tracts with housing unit densities of about 8000 per square mile.) Altogether, this set of three objective density components is able to explain about 13 percent of the variance in expressed levels of community satisfaction.

When the two sets of predictors are combined into a single regression analysis, it is found that crowding and density together are able to explain about 25 percent of the variance in levels of community satisfaction. This is an increment of more than 7 percentage points over the explanatory 
power of the perceptions of crowding alone. This increment, in turn, is more than half of the total predictive power of the set of density components, suggesting that most of the explanatory power of objective density is not mediated by perceptions of crowding.

Further analysis (not shown here) confirms what is suggested by common sense: much of the explanatory power of objective density which is not mediated by perceptions of crowding is associated with economic factors. That is to say, high density housing tends to be housing for lower income households. When the median value of owner occupied units within a census

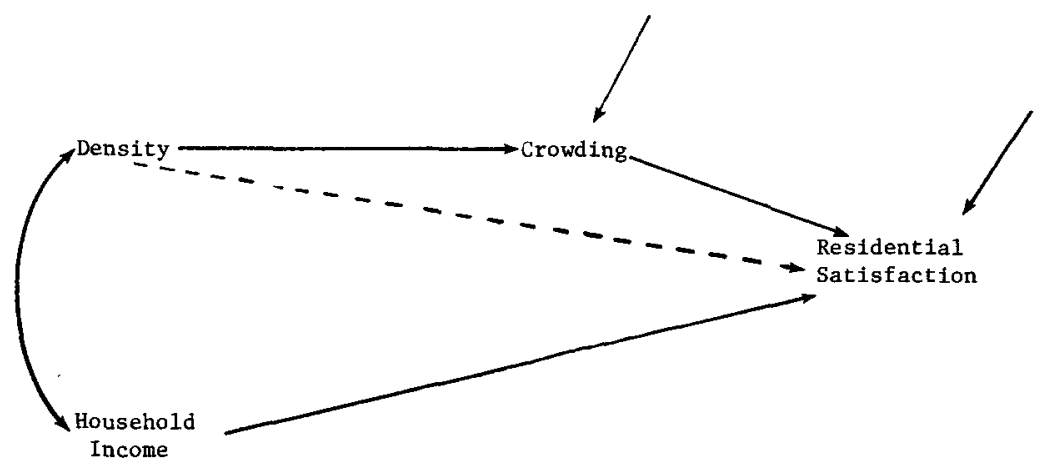

Fig. 1a. Causal model which implies that part of the correlation between density and residential satisfaction is spurious.

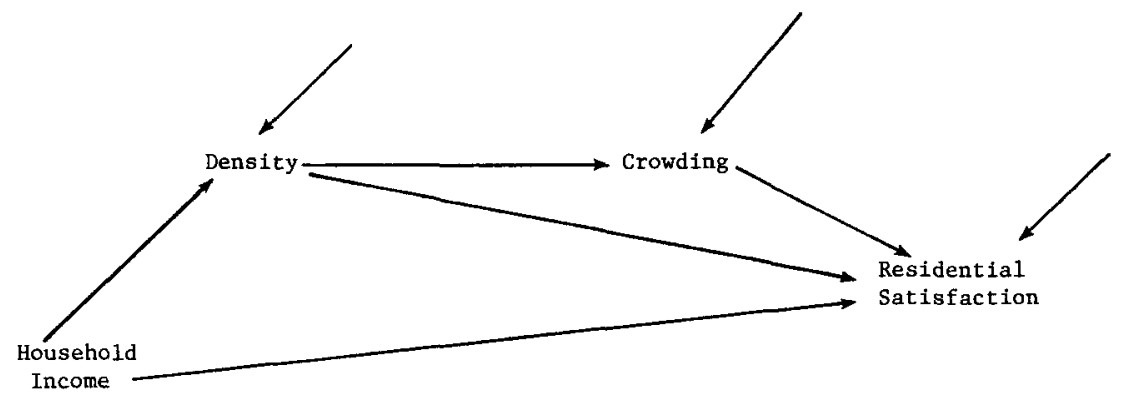

Fig. 1b. Causal model which implies that high density is a consequence of low household income, and that it partially explains the correlation between household income and residential satisfaction. 
tract (or alternatively the median rent paid by renters within the census tract) is controlled, about two thirds of the marginal predictive power of the density measures disappears. One interpretation of this finding is that most of the predictive power of the density measures that is not mediated by perceptions of crowding is spurious, arising from the association between density and economic conditions. The causal model implied is shown in Figure 1a. Of course, it is equally legitimate to conclude from these data that density is merely one of the aspects of low income housing that accounts for the relative dissatisfaction of people who live in low income housing: the causal model implied here is shown in Figure $1 \mathrm{~b}$.

\section{Satisfaction with Neighborhood}

The analysis of satisfaction with the neighborhood is shown in Table V. The

TABLE V

Multivariate regression analyses: Satisfaction with the community as predicted by density and crowding (standardized regression coefficients)

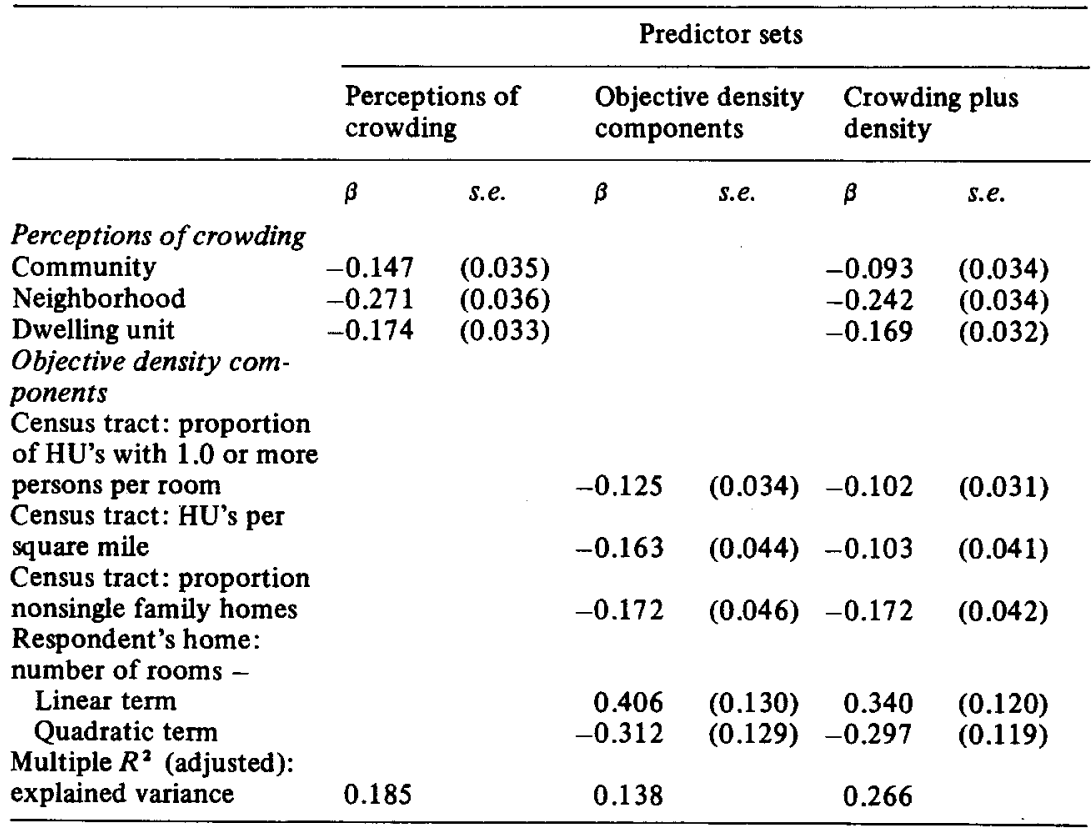


overall pattern is very similar to what was found for satisfaction with the community. The three measures of perceived crowding explain 18.5 percent of the variance in neighborhood satisfaction. The components of density that were found to contribute to neighborhood satisfaction include the proportion of households within the census tract that are overcrowded, the number of household units per square mile within the tract, and the proportion of homes within the tract that are single family units. The number of rooms within the respondent's own home is also an important predictor of neighborhood satisfaction, with the greatest satisfaction being expressed by those living in homes with seven to ten rooms. Together, these four components of objective density account for about 14 percent of the variance in nieighborhood satisfaction.

When the measures of perceived crowding are combined with the components of objective density, about 27 percent of the total variance in neighborhood satisfaction can be explained. As in the case of community satisfaction, more than half of the explanatory power of the objective density measures is apparently not mediated by perceptions of crowding. About half of the explanatory power of the objective density measure that is not mediated by the measures of perceived crowding is associated with an economic variable (median value of owner occupied homes within the census tract), but as in the case of community satisfaction, the causal interpretation of this shared explanatory power is ambiguous.

\section{Satisfaction with Dwelling Unit}

The analysis of the levels of satisfaction expressed with the respondents' own dwelling units is shown in Table VI. The three measures of perceived crowding explain a total of about 21 percent of the variance in satisfaction with the dwelling unit, which is a somewhat higher proportion than these crowding variables were able to explain with respect to community or neighborhood satisfaction. The three aspects of objective density which were found to explain the highest proportion of variance in dwelling unit satisfaction were the density of housing units within the census tract, and two aspects of density within the respondent's own home: number of persons, and the number of persons per room. The number of persons per room is the most important aspect of objective density, but when this factor is controlled, persons living in large households tend to be somewhat more satisfied than 
TABLE VI

Multivariate regression analysis, satisfaction with the dwelling unit as influenced by density and crowding (standardized regression coefficients)

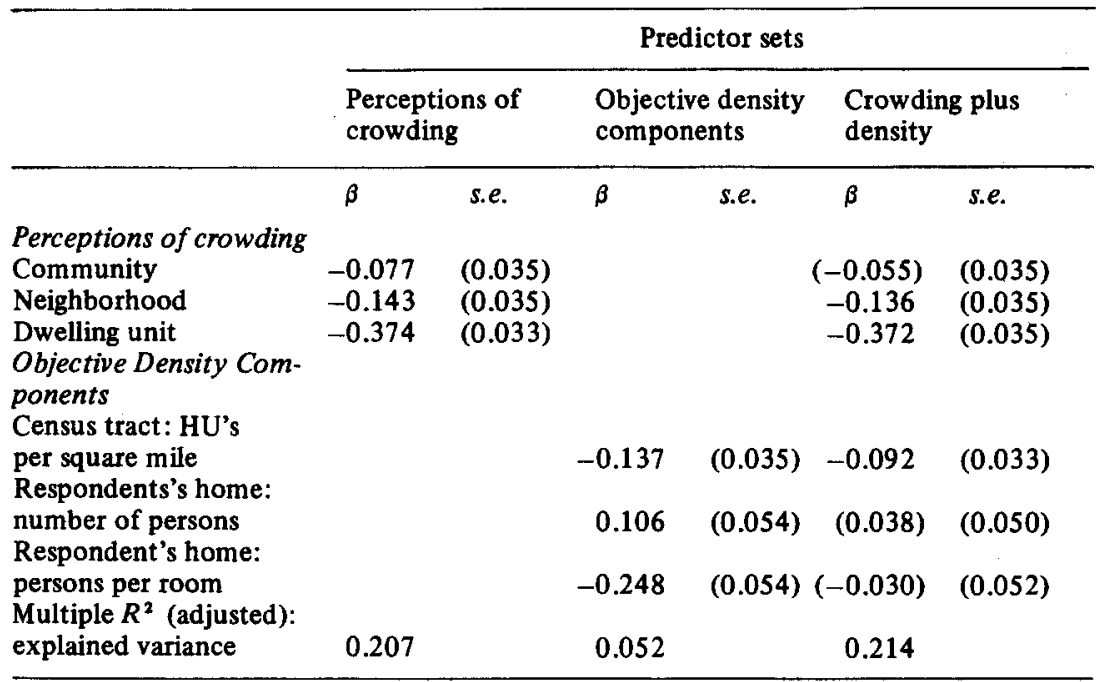

those persons living in small households. Altogether, these components of density are able to account for only about five percent of the total variance in dwelling unit satisfaction, which is less than half the proportion explained by density with respect to satisfaction with the community and with neighborhood. Furthermore, the combined set of crowding and density variables explain less than 1 percentage point more with respect to dwelling unit satisfaction than do the measures of perceived crowding alone. That is to say, density is not very strongly related to satisfaction with the immediate dwelling unit, and almost all of what little explanatory power density does have is apparently mediated by the perceptions of crowding.

\section{Measurement Issues}

The interpretation of the analyses presented thus far is clouded by measurement issues having to do with the reliabilities and validities of the variables used as indicators of the various concepts. In particular, the efficacy of perceptions of crowding as mediating variables between density and residential 
satisfaction may be distorted if responses to subjective questions are influenced by bias of some sort. For example, people may differ in the extent to which they tend to describe their environments in favorable or unfavorable terms, and the measures of crowding, though intended as measures of perceptions, certainly contain an evaluative component as well.

To deal with such measurement issues, a powerful procedure has been developed by. Joreskog and his colleagues (Joreskog, 1973; Joreskog and Sorbom, 1978; see also Long, 1976 for a less technical introduction). This procedure, as implemented in a computer program called LISREL IV, was applied to the present data. The findings are summarized in Figure 2 and the assumptions made to identify the model are given in the footnote to that figure $^{6}$. In words, what this analysis tells us is that the effects of the various density measures on community satisfaction are entirely mediated by the perception of community crowding, and that the effect of community crowding on community satisfaction is considerably stronger than appears from the raw data before taking account of the unreliability of the measures and the assumed response bias. Perceptions of community crowding, in turn, are affected primarily by the density of housing in the census tract, and to a lesser extent by whether the respondent lives in a single or multiple-family building and by the distance from the structure in which the respondent lives to the next structure (a rather different set from those listed in Table IV for the raw data).

Neighborhood satisfaction is only rather weakly influenced by perceived neighborhood crowding, and two aspects of density are estimated to have significant direct effects on neighborhood satisfaction. Several density components have significant effects on perceived neighborhood crowding, including in particular whether the respondent lived in a multiple-family structure and the distance to the next structure.

Satisfaction with one's own dwelling unit is estimated to be strongly influenced by perceived crowding within the home, which in turn is strongly influenced by intrahousehold density. Note, however, that only rather small fractions of the variation in any of the perceptions of crowding are explained by the available density factors, despite having at least attempted to eliminate the diminution in the correlation of observed variables because of their unreliability. 
Fig. 2a-b. LISREL analysis of relationships among density components, perceptions of crowding, and satisfactions with the residential environment.

2a. Causal mode1*

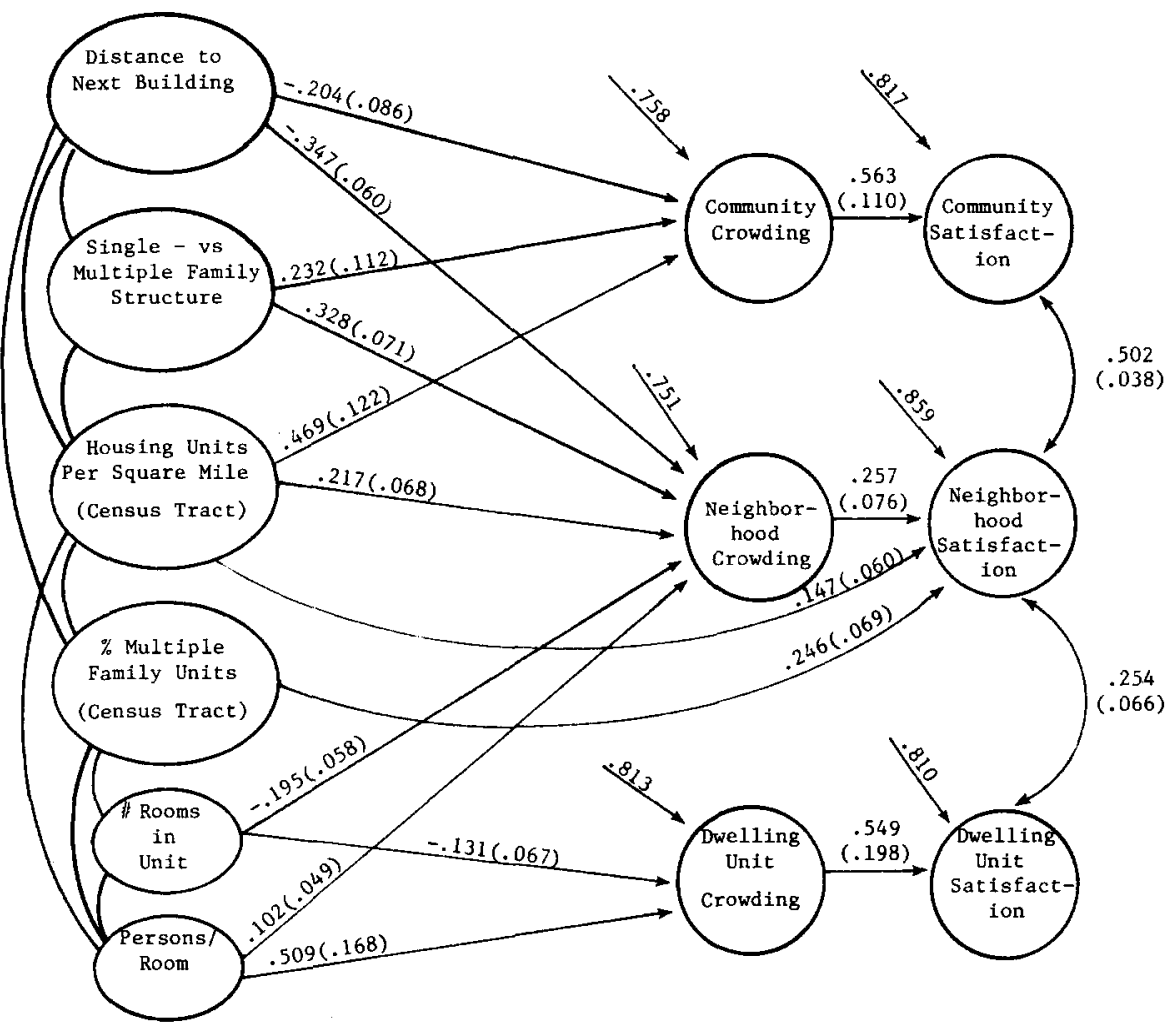

* Paths from perceived crowding at one level of the environment to satisfaction with another level are assumed to be zero. Partial correlations among perceptions of crowding (after removing effects of density) are assumed to be zero. All other paths were left free, but only paths that are estimated to be significantly different from zero are shown in this diagram. 
2b. Measurement Mode1 ${ }^{+}$

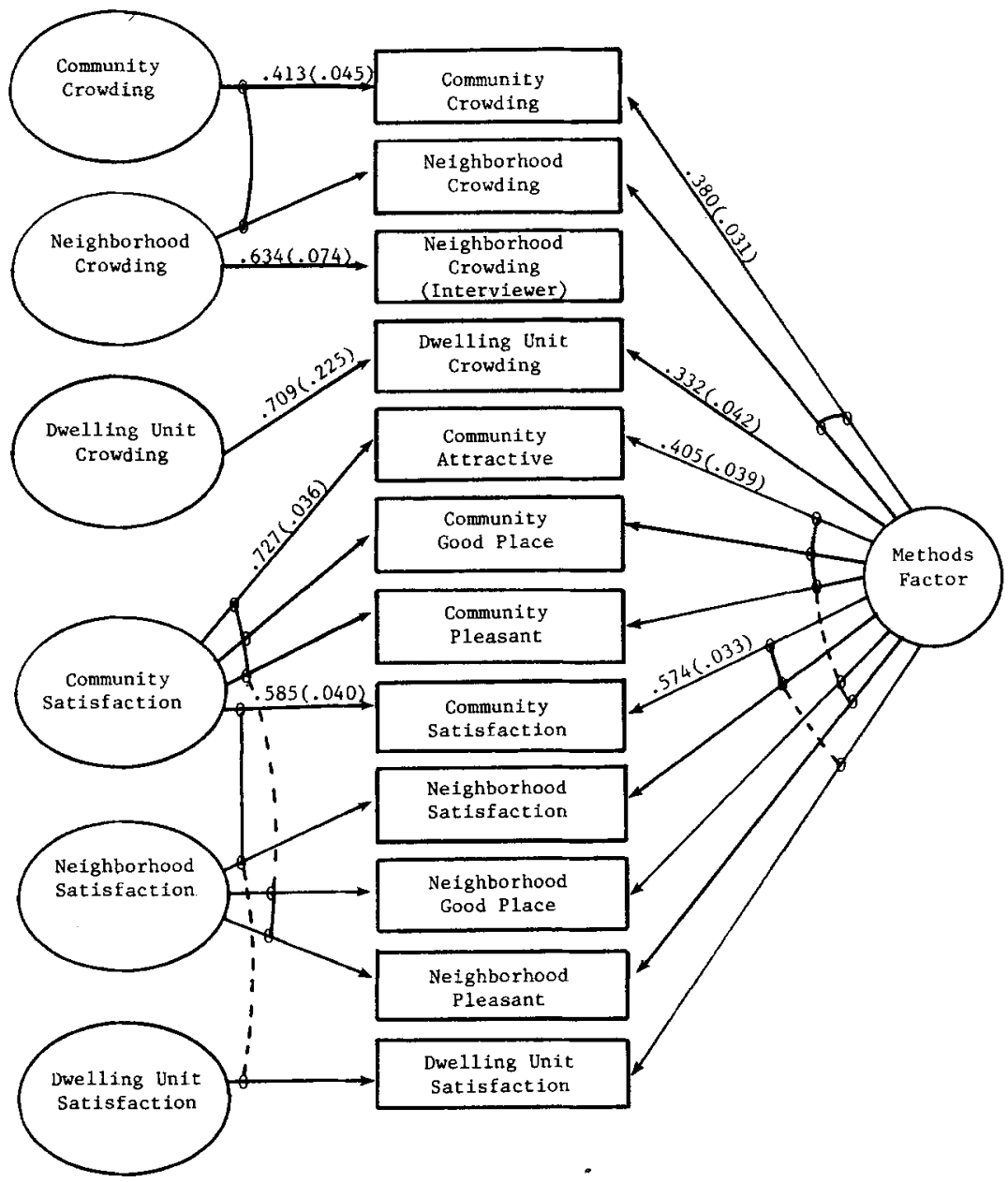

+ This measurement model and the causal model shown in Figure $2 \mathrm{a}$ were estimated simultaneously. All paths not shown were assumed to be zero. Paths constrained to be equal to one another (unstandardized) are shown connected by lines crossing the paths, and the path coefficients are given only for the first of a set of paths so constrained. All of the density measures are assumed to be measured without error, and not shown. 


\section{DISCUSSION}

In a separate analysis of the same data as were used in this paper, it was found that both crowding and overall density may explain a substantial proportion of the relative dissatisfaction with city that is expressed by residents of the central city of Detroit as compared to residents of the suburban areas (Rodgers, 1979). In this paper, the interrelationships between measures of density and of crowding have been examined and their joint effects on community satisfaction considered in greater detail. The findings raise issues that cannot be fully developed in the context of an article, but which should at least be mentioned. The ideas introduced in the following discussion, and their empirical basis, will be explored more fully in a monograph reporting extensive analyses of the Detroit quality of life study (Rodgers and Marans, in preparation).

The general issue that is illustrated by this particular analysis concerns the relationship between objective and subjective indicators of well-being. The findings about the relationship between the objective indicator (density) and the subjective indicator (crowding) can be viewed from at least two fundamentally distinct perspectives, which can be labelled as societal and individual respectively.

From a societal perspective, the findings support the notion that the two types of indicator are compatible. The relationship between density and crowding is not very strong, but it is certainly there, and in the expected direction: people who live in densely populated areas do feel more crowded. Moreover, the subjective indicators provide valuable input for the interpretation of density indicators, in that we have learned what aspects of density are most crucial with respect to feelings of crowdedness. For example, the number of persons per household, and the intrahousehold density (apart from that of the respondent's own household) do not show much relationship to feelings of being crowded, but the number of households per structure is considerably more important.

From the perspective of the individual, and of the psychologist interested in processes involved in evaluating the environment, it is clear that what is measured by objective indicators is only a relatively small part of the explanation for how satisfied a person is with the residential environment. There are numerous other factors involved, not examined in this study, but presumably including adaptation processes, aspiration levels, and all sorts of other 
influences from a person's past experiences and various personality characteristics.

These perspectives are not, of course, incompatible. What matters to the psychologist is that environmental characteristics are only one of a broad set of factors which influence how that environment is evaluated. What matters to those taking the societal perspective is that even though the relationship is weak when analyzed at the individual level, it is there, it is interpretable, and it has implications for environmental design and planning. Nevertheless, while the relationship between objective conditions and subjective evaluations have important implications, it is much less clear that the absolute level of a subjective measure per se has any implications for society.

It can be argued that it is not a proper goal for society to make individuals satisfied. A more reasonable goal would be to attempt to change objective conditions in the direction that citizens prefer. If there are divergencies in such preferences, a proper goal is to provide diverse conditions and assure freedom of access to preferred environments. Moreover, if the preferences of some are in conflict with the needs or rights of others, a proper goal might be the reconciliation of those preferences. But to set about the goal of trying to maximize satisfaction for everyone might well be a thankless task, and one that invites the use of unacceptable means. Society has little or no access to most of the cards in this game: something may be done to modify at least certain environmental conditions, but it may well be that, as suggested by the analyses in this paper, these objective conditions have only a small influence on individual evaluations of the environment. Even more bewilderingly, the very process of improving objective conditions may also increase what is expected, with the end result that objective improvements may have little apparent impact, or even negative impact, on levels of satisfaction. The 'revolution of rising expectations' is most apparent in developing countries, but the same phenomenon pervades developed countries as well, as witnessed by ever new consumer demands to match rising levels of real income.

The foregoing discussion has implications for the collection of what have been called subjective social indicators. Most important, it implies that 'satisfaction' measures (e.g., the mean satisfaction of a population or a subpopulation) are not really social indicators at all, although they may provide valuable inputs into the interpretation of social indicators. This statement depends, of course, on what is meant by 'social indicators'. One useful definition of the term is provided by Land (1971, p. 323): 
I,propose that the term social indicators refer to social statistics that (1) are components in a social system model (including sociopsychological, economic, demographic, and ecological) or of some particular segment or process thereof, (2) can be collected and analyzed at various times and accumulated into a time-series and (3) can be aggregated or disaggregated to levels appropriate to the specifications of the model... . The criterion for classifying a social statistic as a social indicator is its informative value which derives from its empirically verified nexus in a conceptualization of a social process.

Measures of satisfaction have yet to be incorporated in any meaningful way into a social system model of any kind; there is no empirical verification of their place in a conceptualization of any social process. This may merely be the consequence of the relatively short period during which satisfaction studies have been conducted, but it may also be inherent in the nature of satisfaction and its determinants.

Other defintions have, of course, been given, and measures of satisfaction do qualify as social indicators according to some of those definitions - or will when such measures are available as time series. For example, a definition given by Sheldon and Freeman (1970) is that "social indicators are time-series that allow comparisons over an extended period which permit one to grasp long-term trends as well as unusually sharp fluctuations in rates". By most definitions, however, the term 'social indicators' implies that a statistic is relevant to an assessment of how well society is functioning in some respect. The relevance may not be direct - some statistics may be useful because they anticipate, and thus serve to predict, changes in indicators with directly normative interest - but relevance to assessment of societal functioning seems to be a necessary part of the definition if any distinction is to be made between the concept of social indicators and the unbounded set of all possible statistics.

In one sense, satisfaction measures seem to meet the criterion of relevance to societal functioning, since an important, it not the primary, goal of society is to improve the quality of life of its members, and subjective measures are the most direct indicators of the quality of life. On closer consideration, however, satisfaction measures fail to meet this criterion because they capture too much; they are influenced by societal processes, but these effects are mediated by individual characteristics, and are therefore only clouded, and often distorted, images of those processes. Unless and until a much better understanding of the psychological process involved in forming evaluations of the environment is available, and survey measures available for the constructs needed to assess those processes in general population samples, 
satisfaction measures are likely to be weak indicators at best, and misleading indicators at worst, of societal functioning.

One of the most striking generalizations from studies of satisfaction (e.g., Campbell et al., 1976; Andrews and Withey, 1976) is that satisfaction is only weakly related to characteristics of the individual respondent and of his or her life situation. The expected relationships are there: those with higher incomes tend to be more satisfied with a lot of things than are those with lower incomes; those living in large cities are less satisfied with their environments than those living in smaller places; married people tend to be more satisfied with their lives than those who are divorced or separated; and so on. These relationships are all, however, weak - often almost to the point of vanishing behind the curtain of sampling error. Furthermore, when time trends are examined, differences in economic conditions are related to levels of satisfaction of happiness, but only very weakly (cf. Davis, 1975; Easterlin, 1974). And the analysis reported in this paper indicates that perceived crowding is related to objective density in the expected direction, but only weakly.

One interpretation of the weak observed relationships between objective conditions and subjective evaluations was proposed earlier in this discussion: objective conditions are only one determinant, and a rather weak determinant at that, of subjective evaluations, which depend primarily on characteristics unique to the individual such as past experiences and personality traits. The study of satisfaction is an important activity that hopefully will increase our understanding of processes of adaptation and coping, but such studies are only indirectly related to social indicators or to social indicator models, social accounting, and related endeavors. There is little basis for the implicit assumption that differences in satisfaction between subgroups or trends in satisfaction level over time offer any direct messages about societal functioning.

What studies of subjective well-being may be able to provide that is relevant to social indicators is information about what objective conditions are worth measuring and trying to change. Although the relationships between subjective evaluations and objective conditions are weak, they do exist, and the strength of different correlations can be compared to assess the relative importance of different environmental dimensions with respect to subjective well-being. By using multiple-item indices and more careful data collection techniques, and by incorporating measurement issues into the 
analysis of the data, it is possible to increase the validity of the subjective and objective measure and thus reduce the importance of measurement error; by aggregating the subjective responses of several individuals encountering the same objective conditions, it is possible to reduce the 'noise' arising from individual idiosyncrasies in the perceptual and evaluative processes; and both of these approaches will lead to a sharper description of the relationships among a set of objective and subjective measures.

An implication of the foregoing assessment of measures of subjective wellbeing is that such measures provide useful information with respect to social indicators only if they are studied together with measures of objective conditions, since measures of satisfaction and other evaluative statements are useful primarily because of the meaning they give to objective indicators. It may be important to conduct such studies in different countries or in different regions to make comparisons between the populations: objective conditions may be differently weighted by people in different places. Such assessments can be made, however, only if the studies measure both the evaluations and the conditions. It is probably also important to repeat such studies from time to time, not so much for the sake of monitoring satisfaction levels as to look out for changes in the evaluation processes. What was important in 1970 may be irrelevant in 1990 , as new conditions prevail and as people change.

If the preceding remarks seem to imply a defense of existing objective soial indicators, a demurral is in order to correct that impression. Too many statistics are gathered that have no obvious implications for policy or for the quality of life. The divorce rate is an obvious example; does the rising divorce rate imply a lowered quality of life in general, and of marriage relationships in particular, or does it on the contrary imply greater freedom to exit from unhappy marriages and therefore indicate a rising overall quality of life? Another example is the rate of dropping out by high school students. Many educators take the dropout rate as a negative indicator, and measure success of intervention programs in terms of reduced dropout rates, despite an increasing preponderance of evidence that dropping out per se has few if any measurable negative impacts on the individual or, for that matter, on society at large. Both of these examples suggest that for people who find themselves in unsatisfactory situations - marriages, schooling, or whatever - an adaptive solution may be to exit, and outside forces that inhibit such exits may be counterproductive. 
Other examples of social statistics with ambiguous implications include the proportion of married women in the labor force, the distribution of retirement ages, the proportion of households that change place of residence per year, the frequency of visits to a physician or hospital, and the reported crime rate. What is needed in each case is more information so that the indicator can be vested with meaning. In practice, this may mean that multiple indicators are needed, to measure such things as the distribution of retirement according to reason for retirement (was it mandatory, voluntary, due to ill health, or what?); the health of the person before and after medical consultation, and perhaps the health of those who do not seek help; and the ratio of reported to unreported crimes. (The latter example, of course, is one where detailed data are already being collected, through LEAA victimization studies.) And it is here that the study of subjective evaluation fits into an overall social accounting system: by serving as one method to identify important social indicators. In other words, studies of subjective well-being can serve to guide in the selection of the entries that should be incorporated into a social accounts framework, although measures of satisfaction may not themselves be appropriate entries in such a framework.

\section{University of Michigan}

\section{NOTES}

* This research was supported by National Institute of Mental Health Grant No. 1 R01 MH 29278-01, 'Quality of Life Indicators: Analysis of Detroit Data'.

** Willard Rodgers, is Associate Research Scientist in the Survey Research Center, Institute for Social Research, at the University of Michigan. Holder of a Ph.D from the University of Pennsylvania, he has directed research of the quality of American Life, and in particular on the quality of metropolitan life.

1 'Determinant' is placed in quotes because, as the authors point out, the causal relation cannot be proved using the cross-sectional data at their disposal. Furthermore, the relationships they find at the aggregate level (their analysis was based on data for each of 75 community areas in Chicago) would not necessarily hold at the individual level.

${ }_{2}$ These measures included the gross mortality rate, infant mortality rate, incidence of tuberculosis and venereal disease, admission to a hospital for mental disorders, illegitimate birthrate, families with detected juvenile offenders, and admission rate to a prison. The exception, suicide rate, was not related strongly to either the overall measure or to the component, persons per room.

- Specifically, the data are for the Detroit SMSA as it was defined in 1971: Wayne, Oakland, and Macomb counties, all in the state of Michigan.

4 An alternative measure of population density was calculated based on only that portion of the census tract that was used for residential purposes, subtracting land devoted 
to industrial, commercial, park land, or other uses. The correlations between this measure of population density and the components of density and subjective crowding are so similar to the correlations of those measures with the unrefined measure of overall density, that nothing is gained by its use.

5 The exact question read as follows: "How true is this statement: This home has enough space so you can do the things you want to do - without others in the household getting in your way or distracting you. Is that very true, somewhat true, not very true, or not at all true?"'

6 It should also be pointed out that several density measures listed in Table 1 are not included in this analysis. Quadratic terms were omitted as an unnecessary complication at this stage of the analysis, and several others were eliminated because they were found not to contribute a significant incremental affect to those included. Finally, the proportion of overcrowded housing units in a census tract was eliminated after a LISREL analysis revealed it had a negative effect on perceived crowding.

\section{BIB L IO G R A PHY}

Andrews, F.M. and Withey, S. B.: 1976, Social Indicators of Well-Being: Americans' Perceptions of Life Quality (Plenum, New York).

Baldassare, M.: 1978, Residential Crowding in Urban America (University of California Press, Berkeley).

Booth, A. and Cowell, J.: 1976, 'Crowding and health', Journal of Health and Social Behavior 17, pp. 204-220.

Campbell, A., Converse, P., and Rodgers, W. L.: 1976, The Quality of American Life: Perceptions, Evaluations, and Satisfactions (Russell Sage Foundation, New York).

Carnahan, D., Gove, W. R., and Galle, O. R.: 1974, 'Urbanization, population density, and overcrowding: Trends in the quality of life in urban America', Social Forces 53 , pp. $62-72$.

Davis, J. A.: 1975, 'Does economic growth improve the human lot? Yes indeed, about 0.0005 per year', Unpublished paper, prepared for presentation at the International Conference on Subjective Indicators of Quality of Life, Fitzwilliam College, Cambridge, England, September.

Day, A. T. and Day, L. H.: 1973, 'Cross-national comparison of population density', Science 181, pp. 1016-1023.

Easterlin, R. A.: 1974, 'Does economic growth improve the human lot? Some empirical evidence', in P. A. David and H. W. Reder (eds.), Nations and Households in Economic Growth (Academic Press, New York) pp. 89-125.

Fischer, C. S., Baldassare, M., and Ofshe, R. J.: 1975, 'Crowding studies and urban life: A critical review', American Institute of Planners Joumal 41, pp. 406-418.

Freedman, J. L.: 1973, 'The effects of population density on humans', in J. Fawcett (ed.), Psychological Perspectives on Population (Basic Books, New York).

French, J. R. P., Jr., Rodgers, W. L., and Cobb, S.: 1974, 'Adjustment as person-environment fit', in G. V. Colho, D. Hamburg, and J. Adams (eds.), Coping and Adaptation (Basic Books, New York), pp. 316-333.

Galle, O. R., Gove, W. R., and McPherson, J. M.: 1972, 'Population density and pathology: what are the relations for man?', Science 176, pp. 23-30.

Gove, W. R., Hughes, M., and Galle, O. R.: 1979, 'Overcrowding in the home: An empirical investigation of its possible pathological consequences', American Sociological Review 44, pp. 59-80.

Land, K. C.: 1971, 'On the definition of social indicators', The American Sociologist 6 , pp. $322-325$. 
Lawrence, J.E. S.: 1974, 'Science and sentiment: Overview of research on crowding and human behavior', Psychological Bulletin 81 pp. 712-720.

Marans, R.W. and Mandell, L.: 1972, The relative effectiveness of density-related measures for predicting attitudes and behavioral variables', Proceedings of the American Statistical Association, Social Statistics Section, pp. 360-363.

Rapoport, A.: 1975, 'Toward a redefinition of density', Environment and Behavior 7, pp. 133-158.

Rodgers, W. L.: 1980, 'Residential satisfaction in relationship to size of place', Social Psychology Quarterly (forthcoming).

Schmitt, R.C.: 1966, 'Density, health, and social disorganization', Journal of the American Institute of Planners 32, pp. 38-40.

Sheldon, Eleanor B. and Freeman, H. E.: 1970, Notes on social indicators: Promises and potential', Policy Sciences 1, pp. 97-111. 